\title{
The expression and antigenicity identification of recombinant rat TGF- $\beta 1$ in bacteria
}

\author{
GAO Chun FAnG ${ }^{1}$, XIAN TAO KONG ${ }^{1}$, Axel M GRESSNER ${ }^{2}$, RAIF WEISKIRCHEN ${ }^{2, *}$ \\ ${ }^{1}$ Department of Laboratory Medicine, Changzheng Hospital, Second Military Medical University, Shanghai \\ 200003, China \\ ${ }^{2}$ Institute of Clinical Chemistry and Pathobiochemistry, Central Laboratory, RWTH-University Hospital, Pauwelsstr \\ 30, D-52074 Aachen, Germany
}

\begin{abstract}
In order to study structure-function details of TGF- $\beta 1$, the recombinant mature form of rat TGF- $\beta 1$ was expressed in bacteria. Synthesis of the 112 amino-acid carboxyl-terminal part of TGF- $\beta 1$ (amino acid 279390) was controlled by an inducible gene expression system based on bacteriophage T7 RNA polymerase. This system allowed an active and selective synthesis of recombinant TGF- $\beta 1$. The molecular weight of expressed TGF- $\beta 1$ monomer determined on SDS-polyacrylamide gel under reducing conditions was about $13 \mathrm{kD}$. Serial detergent washes combined with a single gel-filtration purification step were sufficient to purify the expression product to homogeneity. Amino-terminal sequencing revealed that the $\mathrm{N}$-terminal of the recombinant protein was identical to the published data. In Western blot analysis the recombinant polypeptide showed excellent antigenicity against polyclonal TGF- $\beta 1$ antibody. The mature recombinant rat TGF- $\beta 1$ expressed in this study provides a useful tool for future detailed structural and functional studies.
\end{abstract}

Key words: $T G F-b 1$, recombinant expression, inclusion bodies, purification, antigenicity.

\section{INTRODUCTION}

Transforming growth factor- $\beta \mathrm{s}$ (TGF- $\beta \mathrm{s}$ ) are a family of $25 \mathrm{kD}$ - polypeptides with multifunctional actions in controlling the growth, differentiation and function of a broad range of target cells of both epithelial and mesenchymal origin[1]. Five distinct TGF- $\beta$ isoforms have been cloned from various sources, among them TGF- $\beta 1$ is the most intensively studied and best characterized one. This cytokine is biological inert when secreted by most tissues in form of the so called latent TGF- $\beta 1$ complex $[2,3]$. Although the release from the latent complex is not fully understood it is most likely that highly regulated proteolytic processings are important to unmask and physiologically activate TGF-

Abbreviations: aa, amino acid(s); FPLC, fast pressure liquid chromatography; IPTG, isopropyl-b-galactopyranoside; $\mathrm{pET}$, plasmid for expression by T7 RNA polymerase; TGF-b1, transforming growth factor $\beta 1$.

* Corresponding author, Tel: +49-241-80-88683, Fax: +49-24188-88512, E-mail: rweiskirchen@post. klinikum. rwth-aachen. de

Received Oct-13-2000

March-20-2001 $\beta 1$. The three-dimensional solution structure of the $25 \mathrm{kD}$ disulfide-linked human TGF- $\beta 1$ homodimer and the crystal structure of TGF- $\beta 2$ [4-8] reveal that TGF $\beta$ s are strikingly similar. However, there are several notable differences in structure and flexibility which may be related to specialized functions of various TGF- $\beta \mathrm{s}[4]$. In an attempt to study the structural and functional details of the mature 25 $\mathrm{kD}$-form of TGF- $\beta 1$, we constructed an expression system for recombinant expression of rat TGF- $\beta 1$ under control of the T7 RNA polymerase in Escherichia coli. For expression of the recombinant protein, the expression plasmid was expressed in bacterial host strain BL21 (DE3) carrying plasmid pLysS with capacity to express lysozyme.

Under reducing conditions the apparent molecular weight of the synthesized TGF- $\beta 1$ monomer is about $13 \mathrm{kD}$. We have shown by protein sequenceing that the $\mathrm{N}$-terminal of the purified recombinant protein is identical to the published data. The recombinant protein showed excellent 
antigenicity against polyclonal antibodies of TGFb1. Due to the high conservation among different species, recombinant rat TGF- $\beta 1$ expressed in this study provides a useful tool for future detailed structural and functional studies of the mammalian mature TGF- $\beta 1$.

\section{MATERIALS AND METHODS}

\section{Construction of a pET expression plasmid en- coding recombinant rat TGF- $\beta 1$}

A polymerase chain reaction was performed using DNA from clone pBS-rTGF- $\beta 1$ as template[9] and oligonucleotides 5' -d (AACAGCTATGACCATGATTACG)-3' (SW001) and 5' -d (GGTGCGCACTGGATACCAACTACTGC)-3' (SW002) as primers. Primer SW001 is complementary to nucleotides 802823 of cloning vector pBluescript IIKS(+) (cf. accession no. X52331) and primer SW002 corresponds to nucleotides 12421267 of the published rat TGF- $\beta 1 \mathrm{cDNA}[9]$ with nucleotide substitutions (underlined) at its 5' end introducing a novel site for AviII. The PCR product was digested with EcoRV (GAT $\downarrow$ ATC) included in the multiple cloning site of vector pBluescriptIIKS $(+)$ and AviII (TGC $\downarrow$ GCA). The 357-bp fragment was ligated into expression plasmid pET3d[10], which had been cut by NcoI (C $\downarrow$ CATGG) and then blunt-ended by filling in overhangs using Klenow DNA polymerase. To rule out PCRinduced mutations and to verify the integrity of the TGF- $\beta 1$ coding region, the entire inserted fragment was determined by cycle sequencing using $\mathrm{pET}$-specific primers and the ABI PRISM BigDye termination reaction kit (PE Applied Biosystems). Resulting cycle sequencing reaction products were purified on Centri-Sep spun columns (Princeton Separations) and separated on the ABI PRISM 310 Genetic Analyzer (PE Applied Biosystems) automatic sequencer. The expression plasmid pET3d-TGF- $\beta 1$ constructed in this way encoded the mature monomeric form of rat TGF- $\beta 1$ protein[9].

\section{Expression and purification of recombinant monomeric TGF- $\beta 1$}

For the expression of rat TGF- $\beta 1$ protein in bacteria, pET3dTGF- $\beta 1$ was transformed into Escherichia coli host strain BL21 (DE3) pLysS carrying an inducible T7 RNA polymerase gene and plasmid pLys encoding lysozyme[10],[11]. A glycerol stock or a single colony of transformed bacteria was used to inoculate $20 \mathrm{ml} \mathrm{ZB}$ medium[10] containing $100 \mu \mathrm{g} / \mathrm{ml}$ ampicillin and $25 \mu \mathrm{g} /$ $\mathrm{ml}$ chloramphenicol. After overnight incubation at $37^{\circ} \mathrm{C}$ and $225 \mathrm{rpm}$ the culture was added to $1 \mathrm{~L}$ of NZCYM medium[12] supplemented with ampicillin $(100 \mu \mathrm{g} / \mathrm{ml})$ and chloramphenicol $(25 \mu \mathrm{g} / \mathrm{ml})$. Cells were grown to an optical density of 0.5 at $600 \mathrm{~nm}$ of and were induced to express rat TGF- $\beta 1$ by the addition of isopropyl- $\beta$-D-thiogalactoside (IPTG) (Roth, Germany) to a final concentration of $0.5 \mathrm{mM}$ and incubation for $3 \mathrm{~h}$. For gel-electrophoretic analysis of successful protein induction, bacteria from $0.5 \mathrm{ml}$ aliquots of the induced and uninduced cultures were pelleted and resuspended in $100 \mu \mathrm{l}$ of protein sample buffer[12]. For protein purification bacterial cells were collected by centrifu- gation (10 min at 4,000 × g), washed once with ice cold PBS (GibcoBRL) and resuspended in $20 \mathrm{ml}$ PBS-buffer and freezed at $-80^{\circ} \mathrm{C}$. For preparation of inclusion bodies bacteria were thawed at room temperature and the mixture was sheared on ice by six high-speed treatments of $15 \mathrm{~s}$ in an Ultra-Turrax dispersing apparatus. After centrifugation for $30 \mathrm{~min}$ at 10,000 $\times \mathrm{g}$ at $4^{\circ} \mathrm{C}$ the pellet was resuspended in $10 \mathrm{ml}$ of TEDG-buffer containing $50 \mathrm{mM}$ Tris- $\mathrm{HCl}$ ( $\mathrm{pH}$ 8.0), 2 mM EDTA, $0.1 \mathrm{mM}$ dithiothreitol and $5 \%$ glycerol. The suspension was sonicated on ice four times for $15 \mathrm{~s}$. After the addition of sodium-deoxycholate to a final concentration of $0.05 \%(\mathrm{w} / \mathrm{v})$, the mixture was incubated for $15 \mathrm{~min}$ at $4^{\circ} \mathrm{C}$ and then centrifuged for $30 \mathrm{~min}$ at $10,000 \times \mathrm{g}$. The pellet was resuspended in $10 \mathrm{ml}$ of buffer TEDG supplemented with $0.05 \%(\mathrm{w} / \mathrm{v})$ sodium-deoxycholate and $1 \%(\mathrm{v} /$ v) NP-40. After $5 \mathrm{~min}$ incubation at $4^{\circ} \mathrm{C}$ the mixture was centrifuged as described above. The final pellet was solubilized in $10 \mathrm{ml} 6 \mathrm{M}$ guanidine hydrochloride (Pierce) supplemented with $0.1 \mathrm{mM}$ DTT and clarified by centrifugation. Recombinant TGF-b1 protein was purified to homogeneity by a single denaturing gel-filtration step using a Superdex $75 \mathrm{HR} 10 \mathrm{~mm} / 30 \mathrm{~cm}$ column in a FPLC system (Pharmacia Biotech) at a flow rate of $0.5 \mathrm{ml} / \mathrm{min}$ in $6 \mathrm{M}$ guanidine hydrochloride/0.1 mM DTT. For amino-terminal sequencing of purified TGF- $\beta 1$ pooled TGF- $\beta 1$ containing fractions were intensively dialyzed against water.

\section{SDS-polyacrylamide gel electrophoresis and immunoblotting}

SDS-polyacrylamide gel electrophoresis was performed using $14 \%(\mathrm{w} / \mathrm{v})$ Tris-glycine gels (Novex) under reducing conditions. Briefly, sheared bacterial pellets with or without induction were subjected to gel electrophoresis. Analytical gels were stained in a solution containing $30 \%(\mathrm{v} / \mathrm{v})$ methanol, $10 \%(\mathrm{v} / \mathrm{v})$ acetic acid and $0.5 \%(\mathrm{w} / \mathrm{v})$ Coomassie brillant blue, and destained in a solution containing $30 \%$ (v/v) methanol and $10 \%(\mathrm{v} / \mathrm{v})$ acetic acid. For immunoblotting, a commercially available rat TGF- $\beta 1$ ( R \& D Systems) was used as standard and positive control. Proteins were transferred to Protran membrane (Schleicher and Schuell) according to standard protocols[12]. The blotted membrane was blocked overnight with $5 \%(\mathrm{w} / \mathrm{v})$ non-fat dry milk in TBST [10 $\mathrm{mM}$ Tris, $\mathrm{pH} 7.6 ; 150 \mathrm{mM} \mathrm{NaCl} ; 0.1 \%$ (v/v) Tween 20] at $4^{\circ} \mathrm{C}$. Membrane was subsequently incubated at room temperature with a 1:200 diluted rabbit polyclonal anti-TGFb1 antibody (Santa Cruz) in $1 \%(\mathrm{w} / \mathrm{v})$ non-fat dry milk in TBST for $2 \mathrm{~h}$ and then with a 1:1000 diluted peroxidase (POD)-labeled anti-rabbit IgG as second antibody (Roche) for $45 \mathrm{~min}$. Membrane was rigorously washed after each incubation. Chemiluminescence detection of POD-labeled secondary antibody was performed using supersignal chemiluminecent substrate (Pierce).

\section{RESULTS}

Construction of a pET expression plasmid encoding recombinant $T G F-b 1$

Mammalian cells synthesize a TGF- $\beta 1$ precursor of 390 amino acids, which contains a N-terminal signal pre-peptide (aa 1-23), a long pro-segment (aa 


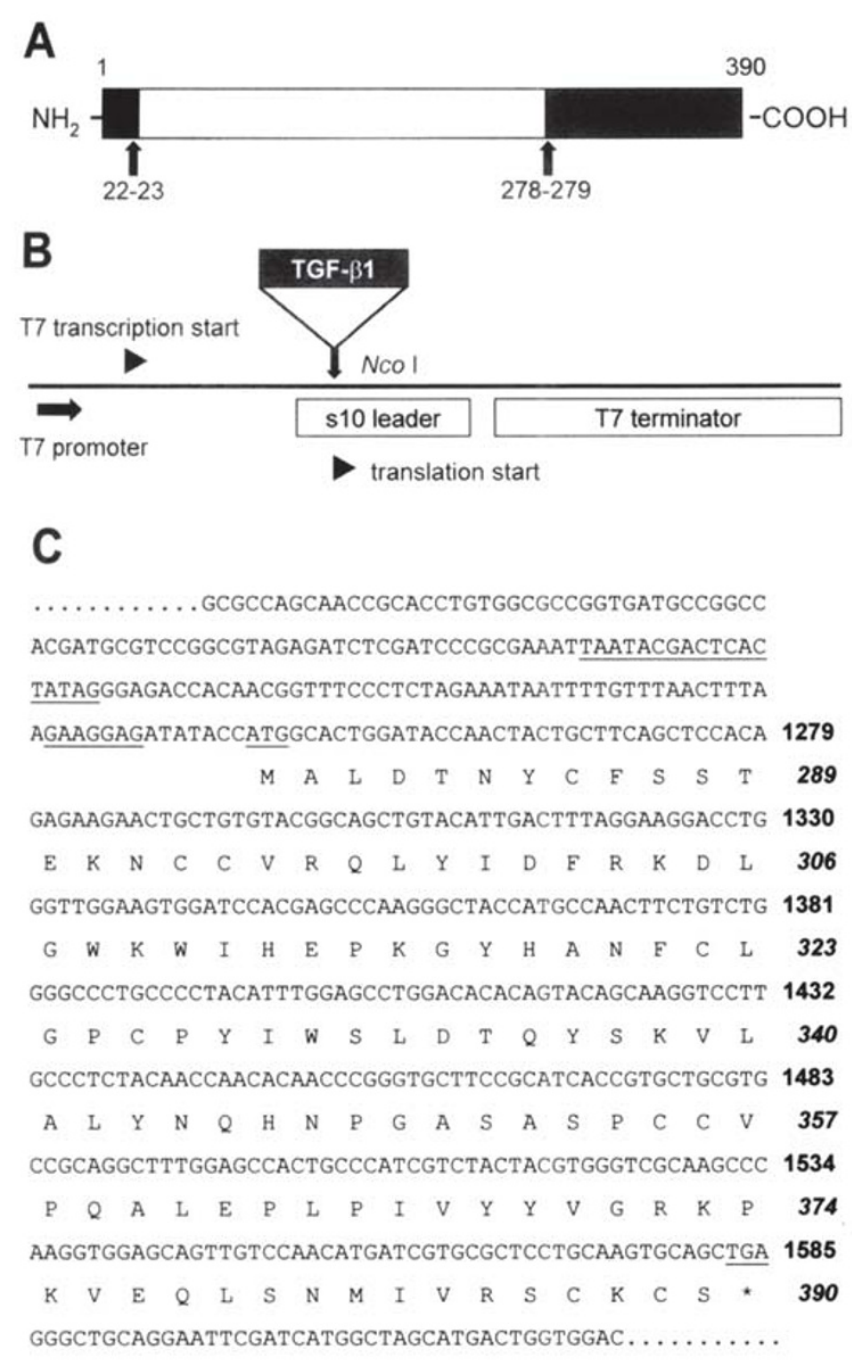

Fig 1 Nucleotide and amino acid sequence of recombinant rat TGF- $\beta 1$ (A) The primary sequence of rat TGF- $\beta 1$ consists of 390 amino acids. The signal sequence (aa 1-22), the pro-sequence (aa 23-278) and the carboxyl- terminal part encoding the mature TGF- $\beta 1$ (aa 279-390) are shown in black, white and grey, respectively. (B) For cloning of expressing vector pET3d-TGF- $\beta 1$ the corresponding 357-bp cDNA fragment (see Material and Methods) was cloned downstream of a T7 promoter into the NcoI site of expression plasmid pET3d. Transcriptional and translational start sites are marked, localization of the s10 leader sequence and the T7 terminator are shown. (C) The expression plasmid pET3d-TGF- $\beta 1$ harbors nucleotides $1247-1585$ of the published rat TGF- $\beta 1$ encoding amino acids 279-390 plus an additional methionine necessary for successful initiation of translation. Numbering in the margin corresponds to nucleotide and amino acids positions of full length rat TGF$\beta 1$ cDNA (cf. accession no. X52498). The T7 RNA polymerase binding site [5'-d(TAATACGACTCACTATA)-3' ], the ShineDalgarno sequence [5' -d(GAAGGAG)-3' ] and codons for translational initiation [5, -d(ATG)-3'] and termination [5' $\mathrm{d}$ (TGA)-3' ] are underlined.
23-278), also called latency-associated polypeptide (LAP) and a 112-amino-acid C-terminal polypeptide (aa 279-390) that constitutes the mature TGF$\beta 1$ monomer (Fig 1A). For the construction of a TGF- $\beta 1$ expression plasmid we cloned part of the rat TGF- $\beta 1$ cDNA (cf. accession no. X52498) corresponding to amino acids 279-390 into the NcoI site of expression vector pET3d[10],[11] (Fig 1B). By this cloning strategy a silent nucleotide exchange from $\mathrm{C}$ to $\mathrm{A}$ at position 1249 according to the published sequence[9] was generated. Vector pET3d is a pBR322-based plasmid containing the $\phi 10$ promoter, the s10 translational initiation leader and a transcription terminator signal from bacteriophage T7[10]. The nucleotide sequence of the pET$3 \mathrm{~d}$ derivative was confirmed by sequencing. The encoded 113-amino acid peptide has a calculated $\mathrm{Mr}$ of 12, 942 and an estimated isoelectric point of 8.21 encompassing amino acids 279-390 of rat TGF- $\beta 1$ including the mature part of TGF- $\beta 1$ and an additional methionine necessary for translational initiation (Fig 1C).

\section{Purification of recombinant rat TGF- $\beta 1$}

The general experimental strategy for expression and purification of TGF-b1 is simply based on sequential detergent washes of the insoluble inclusion bodies and a single gel-filtration purification step under denaturing conditions. For expression of the recombinant protein plasmid pET3dTGF-b1 was transformed in the bacterial host strain BL21 (DE3) pLysS. T7 RNA polymerase was induced by IPTG and recombinant protein synthesis monitored by SDS-polyacrylamide gel electrophoresis under reducing conditions (Fig 2A). The T7 RNA polymerase directed the synthesis of a protein with an apparant molecular weight of 13 , 000, which is in good agreement with the calculated molecular weight of the recombinant TGF$\beta 1$. The synthesized $13-\mathrm{kD}$ protein was obtained largely in the insoluble fraction of the bacterial extract which constituted $29 \%$ of total bacterial protein. Partial purification of recombinant TGF$\beta 1$ was achieved by sequential detergent washes of the insoluble inclusion bodies. To demonstrate the identity of the protein a Western blot analysis was performed (Fig 2B). Inclusion body material from uninduced and induced bacteria as well as a commercially available recombinant human TGF- $\beta 1$ as 
standard were probed with a TGF- $\beta 1$ specific polyclonal antibody. As expected the expressed protein migrating at $\sim 13 \mathrm{kD}$ showed excellent antigenicity indicating the identity of the expressed protein. To purify the expressed protein to homogeneity the inclusion body material was dissolved in a buffer containing $6 \mathrm{M}$ guanidine hydrochloride in the presence of a reducing agent and subjected to denaturing gel-filtration chromatography. A representative elution profil resulting from separation of solubilized inclusion bodies showed only minor con-taminations in the smaller molecular weight range (Fig 2C). The final yield of homoge-

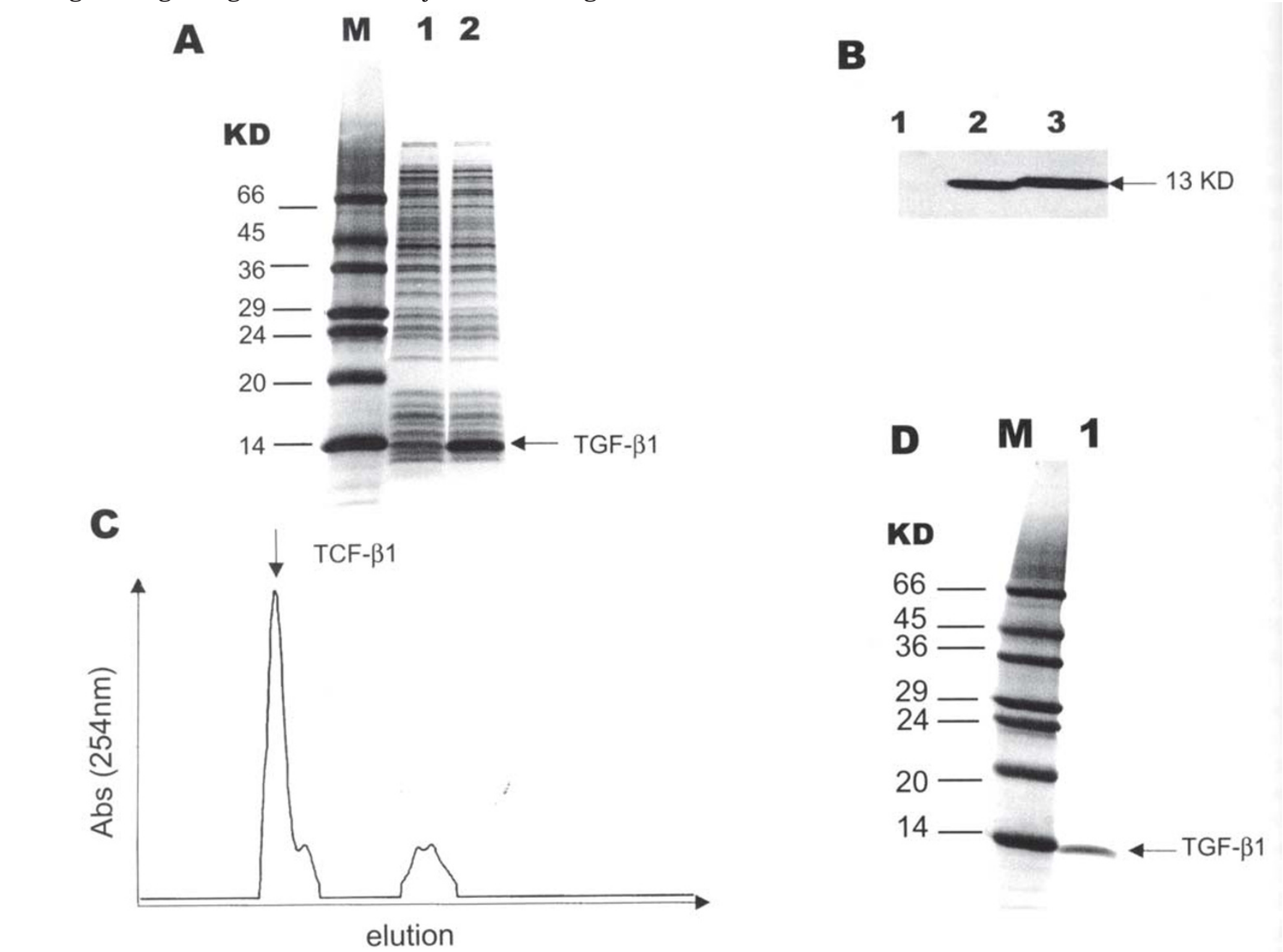

neous rat TGF- $\beta 1$ was approximately $8-10 \mathrm{mg} /$ litre of bacterial culture. The structural integrity and purity of the protein preparation was verified by SDS-polyacrylamide gel electrophoresis (Fig 2D) and amino-terminal sequencing, which revealed that approximately $97 \%$ lacked the initiating methionine.

TGF- $\beta 1$ is a versatile cytokine, which regulates the growth, differentiation and morphology of cells, as well as the extracellular matrix synthesis and proteolysis, and is involved in developmental

\section{DISCUSSION}

Fig 2 Expression and purification of recombinant TGF-b1 (A) SDS- polyacrylamide gel electrophoresis of total protein extracts from BL21 (DE3) pLysS transformed with pET-3d-TGF- $\beta 1$. The bacteria were harvested $3 \mathrm{~h}$ after induction of the T7 RNA polymerase. Proteins isolated prior (1) and after induction (2) with IPTG were fractionated on a 14\% SDS- polyacrylamide gel under reducing conditions and detected by staining with Coomassie brillant blue. Sizes of marker proteins are given in the margin. (B) Immunoblot of inclusion body preparation of non-induced (1) and IPTG-induced (2) bacteria harboring expression plasmid pET3d-TGF- $\beta 1$ using rabbit polyclonal anti-TGF- $\beta 1$ antibodies (Santa Cruz). A commercially available recombinant human TGF- $\beta 1$ (3) was used as positive control. (C) Representative FPLC elution profile of $100 \mu \mathrm{l}$ solubilized recombinant TGF- $\beta 1$ separated on a Superdex $75 \mathrm{HR} 10 \mathrm{~mm} / 30 \mathrm{~cm}$ column at a flow rate of $0.5 \mathrm{ml} / \mathrm{min}$ in $6 \mathrm{M}$ guanidine hydrochloride/0.1 m M DTT. Determination of eluted proteins was carried out at $254 \mathrm{~nm}$. (D) SDS-polyacrylamide gel of $2 \mu \mathrm{g}$ purified recombinant rat TGF- $\beta 1$. Sizes of marker proteins are given in the margin. 
processes. The cloning and sequencing of TGF- $\beta 1$ cDNA-clones from various species had been reported. The 112 amino-acid-long mature form of TGF- $\beta 1$ monomer is initially synthesized as part of a precursor polypeptide. The rat TGF- $\beta 1$ precursor protein consists of 390 amino acid residues which contains a potential signal peptide (aa 1-23), three N-linked glycosylation sites (aa 82-84, aa 136-138, aa 176-178), an RGD integrin binding site (aa 244246) and a tetrabasic cleavage site (aa 275-278) from which the mature TGF- $\beta 1$ peptide can be released[9]. The glycosylation of TGF- $\beta 1$ is restricted to the pro-region, no glycosylation had been found in the mature polypeptide. This makes the recombinant expression of the mature form in prokaryotic system practical.

The cDNA sequence of TGF- $\beta 1$ used in this study codes for the carboxyl-terminal part (aa 279390) of rat TGF- $\beta 1$, the mature form of TGF- $\beta 1$. This 112 amino-acid sequence of TGF- $\beta 1$ harbors the nine cysteine residues which are necessary for formation of four intrachain disulfide bonds (Cys285-Cys294, Cys293-Сys356, Cys322-Сys387, Cys326-Cys389) and an intermolecular cysteine bridge (Cys355) responsible for dimerization[4]. The mature form of monomeric TGF- $\beta 1$ expressed in our system was mainly found in the insoluble fraction of the bacterial lysate. The pET (plasmid for Expression by T7 polymerase) expression vector used in this study is quite competent for protein expression in E.coli. After induction with IPTG, the $13 \mathrm{kD}$-target protein constitutes $29 \%$ of total cell protein.

With serial detergent washes of the bacterial inclusion bodies combined with a gel-filtration purification step of the expressed solubilized protein we were able to purify the monomeric TGF- $\beta 1$ to homogeneity. The identity and purity of recombinant rTGF- $\beta 1$ was confirmed by amino-terminal amino acid sequencing and SDS-polyacrylamide gel electrophoresis. The antigenicity in immunoblotting of this recombinant monomer is similar to that of commercially available recombinant TGF- $\beta 1$ indicating that the recombinant monomer expressed is of high antigenicity. The bacterial expression construct will now allow us to perform several relevant structure-function experiments such as refolding, immunization as antigen, TGF $\beta 1$ blockade, etc.

Although the purified TGF- $\beta 1$ monomer has no definite effects in the Mink cell proliferation assay (data not shown), some evidence revealed that the recombinant TGF-family members like TGF- $\alpha$, TGF- $\beta 2$ and TGF- $\beta 3$ as well as TGF- $\beta 1$ fusion proteins can be successfully expressed in E. coli and renatured into the biologically active form[1316]. Refolding of dimeric biological active forms can be achieved by solubilization, followed by renaturation at $\mathrm{pH} 9$ in the presence of $1.25 \mathrm{M}$ reduced glutathione and $0.25 \mathrm{M}$ oxidized glutathione[13]. Thus, the recombinant expression of TGF- $\beta 1$ in bacteria established in this study may be a promising tool for production of large quantities of TGFb1, which might be biologically active after solubilization and refolding.

\section{ACKNOWLEDGEMENTS}

We thank Prof. Gerhard BUSE (Institute of Biochemistry, RWTH-University Hospital, Aachen, Germany) for amino-terminal protein sequencing, SU Wen Qian (Laboratory of Chemoprevention, NCI/NIH, Bethesda, MD, USA) for sending clone pBS-rTGF- $\beta 1$, and Sabine Weiskirchen for excellent technical assistance.

This project was supported in part by Shanghai Medical Development grant No. ZD99001 and a Grant (SFB-542) from the Deutsche Forschungsgemeinschaft.

\section{REFERENCES}

[1] Lawrence DA. Transforming growth factor- $\beta$ : a general review. Eur Cytokine Netw 1996; 7:363-74.

[2] Lawrence DA, R Pircher, C Kryceve-Martinerie, P Jullien. Normal embryo fibroblasts release transforming growth factors in a latent form. J Cell Physiol 1984; 121: 184-8.

[3] Gentry LE, MN Lioubin, AF Purchio, H Marquardt. Molecular events in the processing of recombinant type 1 pre-pro-transforming growth factor $\beta$ to the mature polypeptide. Mol Cell Biol 1988; 8:4162-8.

[4] Hinck AP, SJ Archer, SW Qian, et al. Transforming growth factor- $\beta 1$ : three-dimensional structure in solution and comparison with the X-ray structure of transforming growth factor- $\beta 2$. Biochemistry 1996; 35:851734.

[5] Daopin S, KA Piez, Y Ogawa, DR Davies. Crystal structure of transforming growth factor- $\beta 2$ : an unusual fold for the superfamily. Science 1992; 257:369-73.

[6] Daopin S, M Li, DR Davies. Crystal structure of TGF- $\beta 2$ refined at 1.8 A resolution. Proteins 1993; 17:176-92.

[7] Schlunegger MP, MG Grutter. An unusual feature revealed by the crystal structure at $2.2 \mathrm{~A}$ resolution of human transforming growth factor- $\beta 2$. Nature 1992; 
358:430-4.

[8] Schlunegger MP, MG Grutter. Refined crystal structure of human transforming growth factor- $\beta 2$ at $1.95 \mathrm{~A}$ resolution. J Mol Biol 1993; 231:445-58.

[9] Qian SW, P Kondaiah, AB Roberts, MB Sporn. cDNA cloning by PCR of rat transforming growth factor $\beta$-1. Nucleic Acids Res 1990; 18:3059.

[10] Studier FW, AH Rosenberg, JJ Dunn, JW Dubendorff. Use of T7 RNA polymerase to direct expression of cloned genes. Methods Enzymol 1990; 185:60-89.

[11] Studier FW, BA Moffatt. Use of bacteriophage T7 RNA polymerase to direct selective high-level expression of cloned genes. J Mol Biol 1986; 189:113-30.

[12] Sambrook J, EF Fritsch, T Maniatis eds. Molecular Cloning: A laboratory manual, Cold Spring Harbor Laboratory: Cold Spring Harbor, NY, 1989.

[13] Derynck R, AB Roberts, ME Winkler, EY Chen, DV
Goeddel. Human transforming growth factor- $\alpha$ : precursor structure and expression in E. coli. Cell 1984; 38: 287-97.

[14] Schlunegger MP, N Cerletti, DA Cox, GK McMaster, A Schmitz, MG Grutter. Crystallization and preliminary $\mathrm{X}$-ray analysis of recombinant human transforming growth factor-b2. FEBS Lett 1992; 303:91-3.

[15] Runser S, N Cerletti. Transforming growth factors $\beta$ : conformational stability and features of the denaturation of recombinant human transforming growth factors $\beta 2$ and $\beta 3$. Biotechnol Appl Biochem 1995; 22:3953.

[16] Tuan TL, DT Cheung, LT Wu, et al. Engineering, expression and renaturation of targeted TGF- $\beta$ fusion proteins. Connect Tissue Res 1996; 34:1-9. 